\title{
Analysis of Hierarchical Routine Data With Covariate Missingness: Effects of Audit \& Feedback on Clinicians' Prescribed Pediatric Pneumonia Care in Kenyan Hospitals
}

\author{
Susan Gachau ${ }^{1,2 *}$, Nelson Owuor ${ }^{2}$, Edmund Njeru Njagi ${ }^{3}$, Philip Ayieko ${ }^{4}$ and \\ Mike English ${ }^{1,5}$
}

${ }^{1}$ Health Services Unit, Kenya Medical Research Institute-Wellcome Trust Research Programme, Nairobi, Kenya, ${ }^{2}$ School of Mathematics, University of Nairobi, Nairobi, Kenya, ${ }^{3}$ Department of Non-Communicable Disease Epidemiology, London School of Hygiene and Tropical Medicine, London, United Kingdom, ${ }^{4}$ Department of Infectious Disease Epidemiology, London School of Hygiene and Tropical Medicine, London, United Kingdom, ${ }^{5}$ Nuffield Department of Medicine, University of Oxford, Oxford, United Kingdom

\section{OPEN ACCESS}

Edited by:

Jim Todd,

London School of Hygiene and Tropical Medicine (LSHTM), United Kingdom

Reviewed by:

Charles Opondo, University of Oxford, United Kingdom Andrew Max Abaasa, Medical Research Council, Uganda

*Correspondence: Susan Gachau sgachau@kemri-wellcome.org

Specialty section: This article was submitted to Digital Health,

a section of the journal

Frontiers in Public Health

Received: 02 February 2019 Accepted: 02 July 2019

Published: 16 July 2019

Citation:

Gachau S, Owuor N, Njagi EN,

Ayieko $P$ and English M (2019) Analysis of Hierarchical Routine Data With Covariate Missingness: Effects of

Audit \& Feedback on Clinicians Prescribed Pediatric Pneumonia Care in Kenyan Hospitals.

Front. Public Health 7:198.

doi: 10.3389/fpubh.2019.00198
Background: Routine clinical data are widely used in many countries to monitor quality of care. A limitation of routine data is missing information which occurs due to lack of documentation of care processes by health care providers, poor record keeping, or limited health care technology at facility level. Our objective was to address missing covariates while properly accounting for hierarchical structure in routine pediatric pneumonia care.

Methods: We analyzed routine data collected during a cluster randomized trial to investigating the effect of audit and feedback (A\&F) over time on inpatient pneumonia care among children admitted in 12 Kenyan hospitals between March and November 2016. Six hospitals in the intervention arm received enhance A\&F on classification and treatment of pneumonia cases in addition to a standard A\&F report on general inpatient pediatric care. The remaining six in control arm received standard A\&F alone. We derived and analyzed a composite outcome known as Pediatric Admission Quality of Care (PAQC) score. In our analysis, we adjusted for patients, clinician and hospital level factors. Missing data occurred in patient and clinician level variables. We did multiple imputation of missing covariates within the joint model imputation framework. We fitted proportion odds random effects model and generalized estimating equation (GEE) models to the data before and after multilevel multiple imputation.

Results: Overall, 2,299 children aged 2 to 59 months were admitted with childhood pneumonia in 12 hospitals during the trial period. 2,127 (92\%) of the children (level 1) were admitted by 378 clinicians across the 12 hospitals. Enhanced A\&F led to improved inpatient pediatric pneumonia care over time compared to standard A\&F. Female clinicians and hospitals with low admission workload were associated with higher uptake of the new pneumonia guidelines during the trial period. In both random effects and marginal model, parameter estimates were biased and inefficient under complete case analysis. 
Conclusions: Enhanced A\&F improved the uptake of WHO recommended pediatric pneumonia guidelines over time compared to standard audit and feedback. When imputing missing data, it is important to account for the hierarchical structure to ensure compatibility with analysis models of interest to alleviate bias.

Keywords: missing data, multiple imputation, PAQC score, routine data, audit and feedback, pediatrics

\section{INTRODUCTION}

Routine data are widely used in many countries to monitor quality of care and to inform intervention programmes for better patients' health outcomes (1).

Routine data can also be used to highlight areas of concern in clinical performance thus prompting actions and strategies to improve practice at individual or institutional levels (2). Prior studies show that quality of care vary across place and time in spite of standard clinical guidelines (3). These variations can be attributed to multiple factors including changes in clinical guidelines, degree of task complexity, and patient's characteristics, clinician characteristics in addition to organizational and contextual factors at hospital level (3-5). Between 2013 and 2014, the Kenya Medical Research InstituteWellcome Trust Research Programme in collaboration with the Ministry of Health, the Kenya Pediatric Association and 14 county-level hospitals initiated a partnership known as the Clinical Information Network (CIN). The main aim of CIN is to collect and use routine pediatric data to promote adoption and adherence to recommended clinical practices through audit and feedback (A\&F) cycles $(3,5-7)$. While such data from multiple sites enhance generalization of results to wider population, it leads to complex hierarchical data structures, for instance, patients clustered within clinicians, who are then clustered within hospitals.

Besides complex structures, routine data are subject to missing information at any level of hierarchy. Missing information may occur due to lack of documentation of care processes by health care providers, poor record keeping, or limited health care technology at facility level $(1,8,9)$. In the occurrence of missing data, appropriate missing data methods at analysis stage are recommended to avoid biased results (10) informing clinical policies and ultimately leading to poor patients care and outcomes (11).

In the recent past, there has been an increase in literature on quality of care among children admitted with common childhood illnesses in low and middle income countries $(3,12-$ 15). However, majority of the studies account for variation at patient and hospital levels ignoring variation due to clinicians characteristics in spite of their critical role in delivery of routine care (16). Besides, missing data is a common problem across these studies. Majority of the studies report using complete case analysis $(13,17,18)$ and multiple imputation $(15,19,20)$. A major limitation of complete case records is biased and inefficient parameter estimates due to information loss. In studies where multiple imputation is used to handle missing data, the nature and details of the imputation model are rarely reported posing uncertainty about conclusions and barriers for replicate analyzes. Furthermore, when missing data occur in multilevel data context, incompatibility between the imputation model and the analysis models potentially leads to biased estimates, underestimated cluster level variances, and overestimated individual level variances (10, 21-23). For example, incompatibilities occur when the imputation model assumes data are single level (i.e., ignoring multilevel structure) while the analysis model of interest is multilevel.

In this study, we aim to address missing covariates while properly accounting for hierarchical structure in inpatient routine data set, that is, patients nested within clinicians who are then nested within hospitals. Specifically, we analyze data from a cluster randomized trial investigating the effect of enhanced audit and feedback on clinicians' prescribed pediatric pneumonia care in Kenyan hospitals. To achieve this objective, we construct and analyze pneumonia Pediatric Admission Quality of Care (PAQC) score adapted to new WHO recommendations on assessment and treatment of inpatient pediatric pneumonia cases. PAQC score is a newly developed ordered composite measure used to benchmark quality of care among children admitted with common childhood illnesses in low and middle income settings.

The remainder of this paper is structured as follows: In the Methods section we present a description of pneumonia trial data followed by statistical analysis methods for cluster correlated and missing data methods, respectively. Thereafter, we present results before and after multiple imputation and conclude with a discussion.

\section{METHODS}

\section{Study Design}

In this study we analyzed data from a cluster randomized trial conducted by KEMRI-Wellcome Trust Research programme between March 2016 and November 2016. Details of the trial and the study population are described in full elsewhere $(5,24)$. In summary, the trial was embedded within the larger CIN study (ongoing) $(6,7,25)$. The primary goal of the trial was to investigate whether enhanced audit and feedback improved quality of inpatient pediatrics pneumonia care (i.e., assessment, diagnosis, and treatment of childhood pneumonia) in Kenyan hospitals following new pneumonia guidelines recommended by the World Health Organization (WHO) in 2013 (26). Six hospitals were randomized to receive a standard audit and feedback report on general inpatient pediatric care (control arm). The remaining six hospitals received a standard audit and feedback report in addition to an enhanced audit and 
feedback targeting assessment, classification and treatment of pneumonia cases (intervention arm) $(5,24)$. Trained data clerks abstracted routine data from the medical records into Research Electronic Data Capture (REDCap) tool after patient's discharge from general pediatric wards. Data abstraction process was guided by a standard operational procedure manual (5). Patients' data spanned history of illness, physical examination, diagnosis, laboratory investigations, treatments, and discharge plans $(5,24)$. Details of admitting clinician including sex and professional qualification were also recorded into a separate database linked to the patients' database by a unique clinician code.

Data quality assurance (DQA) exercises were conducted by CIN research assistants in each hospital every 3 months to check consistencies with data clerk's entries. The Kenya Ministry of Health and Kenya Medical Research Institute's Scientific and Ethical Review Unit approved data collection without individual patient's consent (5).

\section{Outcome: Pneumonia Pediatric Admission Quality of Care Score}

Our outcome of interest was pneumonia PAQC score adapted to 2013 WHO pediatric pneumonia treatment guidelines. As earlier mentioned, PAQC score is a summary measure spanning three quality of care domains namely, assessment, clinical diagnosis, and treatment of common childhood illnesses including pneumonia, malaria, diarrhea, and dehydration. Details on PAQC score construction and validation are described in full elsewhere $(12,27)$. With regard to pneumonia PAQC, there are three binary subcomponents in the assessment domain. The first subcomponent represents assessment and documentation of two primary signs and symptoms required for pneumonia identification (i.e., presence of cough or difficulty in breathing). The value 1 in the binary indicator denotes documentation of both cough and difficulty in breathing as either present or absent while 0 denotes lack of documentation of least one primary sign and symptom in a patient's medical record.

The second binary indicator represents assessment and documentation of secondary signs and symptoms required for pneumonia severity classification (i.e., chest indrawing, respiratory rate, grunting, central cyanosis, oxygen saturation, ability to drink, or altered level of alertness). The value 1 in the binary indicator denotes documentation of all secondary signs and symptoms, respectively, while 0 denotes lack of documentation of least one secondary signs and symptom. The third binary indicator of the assessment domain corresponds to 1 when primary and secondary pneumonia signs and symptoms (all primary and secondary signs and symptoms combined) are documented and 0 otherwise (26).

The second PAQC score domain entails integration of information on presenting signs and symptoms by admitting clinician to correctly diagnose and classify pneumonia severity (i.e., severe pneumonia or pneumonia). For example, pneumonia was the correct diagnosis for a child who, in addition to cough and/or difficult breathing (primary signs), presented with lower chest indrawing or respiratory rate $>50$ for patients aged 2-11 months (or respiratory rate $<40$ for patients aged $12-59$ months) in the absence of all other secondary signs and symptoms. In this study, a binary indicator was created with value 1 representing correct pneumonia severity classification (i.e., is, pneumonia severity documented in the medical record by the admitting clinician was in line with severity implied by presenting signs and symptoms) and 0 representing misclassified pneumonia severity.

The third PAQC score domain consists of two binary indicators. The first binary variable indicates whether oral amoxicillin was prescribed for pneumonia cases (denoted by 1 ) or not (denoted by 0 ). The second binary variable indicates whether oral amoxicillin was prescribed according to guideline recommended doses (26). In order to determine correctness of the dose, we created a new variable "dose per kilo body weight" using actual dose given at point of care, patient's weight, and frequency of administration. Among pediatric pneumonia cases, the recommended oral amoxicillin dose should range between 32 and 48 international units per kilogram (IU/Kg) every $12 \mathrm{~h}$. The new variable was then transformed into a binary variable with 1 representing correct dose (that is, dose per kilo body weight and frequencies of administration are in line with guidelines recommendations) and 0 representing incorrect dose (incorrect in either dose per kilo body weight or frequency of administration) or missing dose. Subsequently, we summed all the six binary components across domains to obtain PAQC score; an ordinal outcome on a 7-point scale. We constructed pneumonia PAQC score at patient level. A minimum score of zero corresponded to inappropriate pneumonia care and maximum score of six represented complete adherence to new pneumonia guidelines across domains of care. To assess performance in terms of adherence to pediatric pneumonia guidelines during the trial period, we calculated and plotted the LOESS smoothing curves and the corresponding 95\% confidence bands for the mean monthly PAQC score for each intervention arm.

\section{Covariates}

The covariates of interest were intervention arm, follow up time in months with their interaction, hospital malaria prevalence status, and hospital admission workload. At clinician level, gender, and cadre were considered (here cadre refers to clinician's level of training that is, clinical officers with diploma-level training and medical officers with a bachelor's degree level training). At patient level, we considered sex, number of comorbid illnesses, and age at admission. Prior to analysis, we converted age for all the patients into months before categorizing them into two age groups that is, patients aged 2-11 months and patients aged 12-59 months. With regard to comorbidities, we determined the total number of clinical diagnoses documented in patient's medical records. The diagnoses of interest included malaria, malnutrition, HIV, Asthma, Tuberculosis (TB), rickets, anemia, diarrhea, and dehydration. For each patient, we created separate binary variables for the diagnosis above with value 1 denoting the presence of a disease and 0 denoting absence of a disease. We then summed the binary indicators and categorized patients into four groups, that is those with $0,1,2,3$ or more comorbidities, respectively. 


\section{Missing Data Concepts}

In the analysis of partially observed data, assumptions were made about the missingness mechanism generating the data (10). Suppose $Y$ (representing both response and independent variables) is an $N \times p$ matrix denoting a hypothetical data set containing $\mathrm{p}$ variables $(j=1, \ldots, \mathrm{p})$ for the $i$ th study subject, $(i=1,2,3, \ldots, N)$. For each study subject, $Y_{i}$ can be partitioned into observed and missing components denoted by $Y_{i}{ }^{o b s}$ and $Y_{i}^{\text {miss }}$, respectively. Further letting a missingness indicator $R_{i}$ take the value 1 if $Y_{i}$ is observed and 0 if $Y_{i}$ is missing. Then according to Rubin (28) data are said to be missing completely at random (MCAR) when the probability of missing values in variable is independent of the variable itself or any other observed variable in the data set that is, $P\left(R_{i} \mid Y_{i}{ }^{\text {miss }}, \mathrm{Y}_{i}{ }^{\text {obs }}\right)=P\left(R_{i}\right)$. When the probability of missing values in a variable does not depend on the variable of interest but are conditionally dependent on other observed variables in the data set, then data are said to be missing at random (MAR) and denoted by $P\left(R_{i} \mid Y_{i}{ }^{\text {miss }}, \mathrm{Y}_{i}{ }^{\text {obs }}\right)=$ $P\left(R_{i} \mid Y_{i}{ }^{o b s}\right)$. When MAR assumption does not hold, then data are said to be Missing Not at Random (MNAR). MNAR mechanism occurs when the missingness depends on the actual value of the missed observation (10).

\section{Investigating the Missing Data Mechanism}

Before analyzing partially observed data, it was important to investigate plausible missing data mechanisms $(10,29)$. In this study we generated binary missingness indicators $\left(R_{i}\right)$ for partially observed variables in the pneumonia trial data set. The binary missingness indicators were analyzed separately using a logistic regression model below

$$
\operatorname{logit}\left[P\left(R_{i}\right)\right]=X_{i} \beta
$$

where $X_{i}$ is a vector of fully observed variables for the ith subject. The vector $\beta$ denotes fixed regression parameters to be estimated. When the probability of missingness is independent on fully observed variables $(P$-values for the regression coefficients $>0.05$ ), a variable is said to be MCAR. On the other hand, when the probability of missingness is dependent on fully observed variables ( $P$-values for the regression coefficients $<0.05$ ), then MAR assumptions holds and restricting analysis to complete observations yields bias and inefficient estimates $(10,29,30)$. Similarly, when the probability of missingness is dependent on fully observed covariates but independent of the response variable, then covariate dependent MAR assumptions holds and restricting analysis to complete observations yields unbiased but inefficient estimates due to information loss (10, $29,30)$. We also used graphical methods to investigate missing data patterns underlying pneumonia trial data (Figure A1 in Supplementary Material).

\section{Multiple Imputation}

Multiple imputation (MI) involves substituting each missing value with a set of plausible values given the observed data and an imputation model $(10,31)$. MI is commonly used assuming a MAR mechanism but can also be used when data are MNAR. Multiple imputed data sets are then analyzed using standard methods and results pooled into a single inference using Rubin's Rule (32). Multiple imputation is preferred over other missing data methods such as list wise or pairwise deletion because uncertainty about the missing values is taken into account (10, $23,30,31,33)$. Additionally, MI separates imputation phase from analysis phase therefore allowing inclusion of auxiliary variables in the imputation model that are predictive of missing variables and the missingness mechanism $(10,23,27,33-35)$.

In this study, we imputed missing level 1 and level 2 variables within the joint modeling framework where replacement values are drawn from a multivariate normal distribution in a single step. Multilevel MI was implemented in the newly developed jomo and mitmil packages in $\mathrm{R}$ (version 3.4.3) which allows imputation of categorical variables with more than two levels in the second and higher levels of the multilevel structure (36). For the $i$ th patient nested within $j$ th clinician in hospital $l$, we defined a two level JM imputation model corresponding to

$$
\begin{aligned}
Y_{i, j, l}^{(1)} & =X_{i, j, l}^{(1)} \beta^{(1)}+b_{j, l}^{(1)}+e_{i, j, l}^{(1)} \\
Y_{j, l}^{(2)} & =X_{j, l}^{(2)} \beta^{(2)}+b_{j, l}^{(2)} \\
e_{i, j, l} & \sim N\left(0, \sigma_{e}^{2}\right), \text { and }\left(b_{j, l}^{(1)}, b_{j, l}^{(2)}\right) \sim N\left(0, \Sigma_{b}\right)
\end{aligned}
$$

where $Y_{i, j, l}{ }^{(1)}$ and $Y_{j, l}{ }^{(2)}$ are vectors of partially observed level 1 variables (patient's sex) and level 2 variables (clinician's sex and cadre), respectively. Predictor variables $\left(X_{i, j, l}{ }^{(1)}\right)$ of missing patient's sex included fully observed follow-up time interacted with feedback arm, hospital admission workload and hospital malaria prevalence status, patient's PAQC score, patient's age and number of comorbid illnesses. Level 2 predictors $\left(X_{j, l}{ }^{(2)}\right)$ for missing clinicians' sex and cadre included follow-up time interacted with feedback arm, hospital admission workload, and hospital malaria prevalence status. Column vectors $\beta^{1}$ and $\beta^{2}$ denote level 1 and level 2 fixed effects, respectively. A clinician random intercept $\left(b_{j, l}\right)$ was included to account for clustering at clinicians' level and to ensure compatibility with substantive models of interests. A burn-in of 1,000 updates and a 1,000 iterations between each of the 30 imputations were considered. We used trace plots to assess convergence (37). Final estimates were pooled according Rubin's rules.

\section{Statistical Analysis}

We considered two model families to analyze pneumonia trial data, that is, generalized estimating equations (GEE) and random effects models. The random effects and GEE models differ in terms of estimation and interpretation of parameter estimates (30). We considered both models in order to assess the stability of inferences and conclusions within and across the two methods before and after multiple imputation.

\section{Generalized Estimating Equations (GEE) Model}

Generalized estimating equations (GEE) proposed by Liang and Zeger (38) is a quasi-likelihood method for modeling correlated responses within the marginal (population averaged) family of models $(29,30)$. In GEE model a working correlation structure is adopted. However, the parameter estimates in GEE model are 
consistent even when the association structure is misspecified $(29,39)$. A GEE model is given by

$$
h^{-1}\left\{E\left(Y_{i} \mid X_{i}\right)\right\}=X_{i} \beta
$$

where the link function $h^{-1}(\bullet)$ is a known function, $X_{i}$ is a design matrix for the fixed effects and $\beta$ is the vector of unknown regression parameters. The vector of regression parameters is interpreted in terms of average response over the population rather than prediction of the effect of changing covariates on a given study subject (29).

When the responses are ordered and the proportional odds assumptions of parallel logits hold, the cumulative logits (proportional odds) model is considered (40). For instance, considering ordered pneumonia PAQC score (outcome) for the $i$ th patient nested within $j$ th clinician in hospital $l$, the proportional odds GEE model of interest corresponds to

$$
\begin{aligned}
& \text { logit }\left[P\left(Y_{\text {PACQ Score }: i, j, l} \leq k\right)\right]=\alpha_{k}+\beta_{1} X_{\text {age group }: i, j, l} \\
& +\beta_{2} X_{\text {patient's sex }: i, j, l}+\beta_{3} X_{\text {comobidity }: i, j, l}+\beta_{4} X_{\text {clinician's cadre }: j, l} \\
& +\beta_{5} X_{\text {clinician's sex }: j, l}+\beta_{6} X_{\text {admission workload }: l} \\
& +\beta_{7} X_{\text {malaria prevalence }: l}+\beta_{8} X_{\text {time in months }: l} * X_{\text {trial arm }: l}
\end{aligned}
$$

where $\alpha_{k}, k=1,2,3,4,5,6$ are PAQC score intercepts and $\beta^{\prime} s$ are regression coefficients common across all $k-1$ cumulative logits.

\section{Random Effects Model}

In contrast to population-averaged models, random effects models are useful when drawing inferences with respect to the subject-specific parameters. Given the covariates and random effects, the responses are assumed to be conditionally independent in this model $(29,30)$. A random effects model is denoted by

$$
\begin{array}{r}
h^{-1}\left\{E\left(Y_{i} \mid X_{i}\right)\right\}=X_{i} \beta+Z_{i} b_{i} \\
b_{i} \sim N(\mathbf{0}, \Sigma)
\end{array}
$$

where $h^{-1}(\bullet)$ is a known link function, $X_{i}$ and $Z_{i}$ are design matrices for the fixed effects and random effects while $\beta$ and $b_{i}$ are vectors of fixed and random parameters, respectively. The vector $b_{i}$ is assumed to be sampled from a multivariate normal distribution with mean vector $\mathbf{0}$ and covariance matrix $\Sigma$. The vector of regression parameters $(\beta)$ has subject specific interpretation in terms of the transformed mean response for in individual. Considering pneumonia trial data with ordinal PAQC score as above, proportional odds random intercepts model of interest corresponds to

$$
\begin{aligned}
& \operatorname{logit}\left[P\left(Y_{P A C Q} \text { Score }: i, j, l \leq k\right)\right] \\
& =\alpha_{k}+\beta_{1} X_{\text {age group }: i, j, l}+\beta_{2} X_{\text {patient's sex }: i, j, l} \\
& +\beta_{3} X_{\text {comobidity: } i, j, l}+\beta_{4} X_{\text {clinician's cadre }: j, l}+\beta_{5} X_{\text {clinician's sex }: j, l} \\
& +\beta_{6} X_{\text {admission workload }: l}+\beta_{7} X_{\text {malaria prevalence }: l} \\
& +\beta_{8} X_{\text {time in months }: l} * X_{\text {trial arm }: l}+b_{j l}
\end{aligned}
$$

where $\alpha_{k}, k=1,2,3,4,5,6$ are PAQC score specific intercepts, $\beta^{\prime}$ s are estimated regression coefficients (common across all $k-1$ cumulative logits) and $b_{j, l}$ are clinician's random intercepts. Hospital level random effects were not considered in these analyses due to the few number of clusters.

\section{Statistical Tests for Multiple Parameters}

We used Wald tests and likelihood-ratio tests to determine covariates with statistically significant effect on pneumonia PAQC score. The likelihood-ratio tests was used to test for statistical significance of covariates in the random effects models $(10,41,42)$. On the other hand, Wald tests suggested by Rubin $(10,41)$ was used for the GEE model. The full (saturated) models contained all the covariates while the reduced (null) models dropped one covariate at a time. The tests were conducted on complete case records and after multiple imputation. Details on multi-parameter hypothesis tests after MI using Wald tests and likelihood-ratio tests are available in Carpenter and Kenward (10, p. 53-54) and Van Buuren (42, p. 157-158). All analyses were conducted in $\mathrm{R}$ version 3.4.3. A $5 \%$ level of significance was considered under complete case analysis and after MI of missing covariates.

\section{RESULTS}

\section{Descriptive Summaries}

In total, 2,299 children aged 2-59 months were admitted in general pediatric wards with childhood pneumonia in 12 CIN hospitals during the trial period. We linked patients and clinicians' databases using unique clinician code present in both databases with a success rate of $92.5 \%(2,127 / 2,299)$ after exclusion of 172/2,299 case records lacking admitting clinician's information. This resulted to three levels of clustering i.e., 2,127 patients admitted by 378 clinicians in 12 hospitals. Of the 2,127 pneumonia cases, 953/2,127 (44.8\%) were admitted in six hospitals assigned to enhanced A\&F (intervention) arm. The number of pneumonia cases varied across hospitals with a range of 42-356 patients (Table 1).

Five out of 12 hospitals were drawn from high malaria endemic regions (three control and two intervention hospitals) while the remaining seven hospitals (four control and three intervention hospitals) were drawn from low malaria regions in Kenya (25). Furthermore, four in 12 hospitals were high admission workload hospitals that is, more than 1,000 pediatric admissions per annum (three control and one intervention hospitals) while 8/12 were low admission workload hospitals i.e., $<1,000$ pediatric admissions per annum (three control and five intervention hospitals) irrespective of admission diagnosis. On average, there were 32 clinicians per hospital with a standard deviation of nine clinicians. The number of patients per clinician ranged between 3 and 46. Majority of the admitting clinicians were clinical officer interns at $48.7 \%$ (185/378) followed by Medical officer interns at $26.2 \%$ (99/378). Clinical officer and medical officers accounted for $1.6 \%$ (6/378) each. Approximately, 21.9\% (83/378) and 21.7\% (82/378) clinicians had missing gender and cadre, respectively (Table 1). In subsequent analyses we grouped clinicians into two cadres from the initial four. That is, clinical officers (CO) combining clinical officers and clinical officer interns and medical officers 
TABLE 1 | Descriptive characteristics of hospitals, clinicians and patients in pneumonia trial data.

\begin{tabular}{|c|c|c|c|c|c|c|c|c|c|c|c|c|c|}
\hline & H1 & H2 & H3 & H4 & H5 & H6 & H7 & H8 & H9 & H10 & H11 & $\mathrm{H} 12$ & Total \\
\hline Enhanced A\&F arm & No & Yes & No & No & Yes & Yes & Yes & Yes & No & No & No & Yes & \\
\hline Admission workload & Low & Low & High & Low & Low & High & Low & Low & Low & High & High & Low & \\
\hline Malaria prevalence & High & Low & High & Low & Low & Low & High & High & Low & Low & Low & High & \\
\hline $\begin{array}{l}\text { Pneumonia admissions, } \\
n(\%)\end{array}$ & $\begin{array}{l}132 \\
(6.21)\end{array}$ & $\begin{array}{c}215 \\
(10.11)\end{array}$ & $\begin{array}{l}210 \\
(9.87)\end{array}$ & $\begin{array}{c}243 \\
(11.42)\end{array}$ & $\begin{array}{l}110 \\
(5.17)\end{array}$ & $\begin{array}{c}356 \\
(16.74)\end{array}$ & $\begin{array}{c}63 \\
(2.96)\end{array}$ & $\begin{array}{c}167 \\
(7.85)\end{array}$ & $\begin{array}{c}88 \\
(4.14)\end{array}$ & $\begin{array}{l}172 \\
(8.09)\end{array}$ & $\begin{array}{c}329 \\
(15.57)\end{array}$ & $\begin{array}{c}42 \\
(1.97)\end{array}$ & $\begin{array}{r}2,127 \\
(100)\end{array}$ \\
\hline $\begin{array}{l}\text { Patients aged } 2-11 \text { months, } \\
n(\%)\end{array}$ & $\begin{array}{c}44 \\
(33.3)\end{array}$ & $\begin{array}{c}79 \\
(36.7)\end{array}$ & $\begin{array}{c}71 \\
(33.8)\end{array}$ & $\begin{array}{c}89 \\
(36.6)\end{array}$ & $\begin{array}{c}49 \\
(44.6)\end{array}$ & $\begin{array}{c}193 \\
(54.5)\end{array}$ & $\begin{array}{c}22 \\
(34.9)\end{array}$ & $\begin{array}{c}70 \\
(41.9)\end{array}$ & $\begin{array}{c}45 \\
(51.1)\end{array}$ & $\begin{array}{c}99 \\
(57.6)\end{array}$ & $\begin{array}{c}129 \\
(39.2)\end{array}$ & $\begin{array}{c}13 \\
(30.95)\end{array}$ & $\begin{array}{c}903 \\
(42.5)\end{array}$ \\
\hline $\begin{array}{l}\text { Patients aged 12-59 } \\
\text { months, } n(\%)\end{array}$ & $\begin{array}{c}88 \\
(66.7)\end{array}$ & $\begin{array}{c}136 \\
(63.3)\end{array}$ & $\begin{array}{c}139 \\
(66.2)\end{array}$ & $\begin{array}{c}154 \\
(63.4)\end{array}$ & $\begin{array}{c}61 \\
(55.5)\end{array}$ & $\begin{array}{c}162 \\
(45.5)\end{array}$ & $\begin{array}{c}41 \\
(65.1)\end{array}$ & $\begin{array}{c}97 \\
(58.1)\end{array}$ & $\begin{array}{c}43 \\
(48.9)\end{array}$ & $\begin{array}{c}73 \\
(42.4)\end{array}$ & $\begin{array}{l}200 \\
(60.8)\end{array}$ & $\begin{array}{c}29 \\
(69.1)\end{array}$ & $\begin{array}{l}1,224 \\
(57.5)\end{array}$ \\
\hline Male patients, $n(\%)$ & $\begin{array}{c}80 \\
(60.6)\end{array}$ & $\begin{array}{c}118 \\
(54.9)\end{array}$ & $\begin{array}{c}103 \\
(49.1)\end{array}$ & $\begin{array}{c}138 \\
(56.8)\end{array}$ & $\begin{array}{c}55 \\
(50.0)\end{array}$ & $\begin{array}{c}194 \\
(54.5)\end{array}$ & $\begin{array}{c}35 \\
(55.6)\end{array}$ & $\begin{array}{c}100 \\
(59.9)\end{array}$ & $\begin{array}{c}42 \\
(47.7)\end{array}$ & $\begin{array}{c}95 \\
(55.2)\end{array}$ & $\begin{array}{c}181 \\
(55.1)\end{array}$ & $\begin{array}{c}23 \\
(54.8)\end{array}$ & $\begin{array}{c}1,164 \\
(54.72)\end{array}$ \\
\hline Female patients, $n$ (\%) & $\begin{array}{c}52 \\
(39.4)\end{array}$ & $\begin{array}{c}97 \\
(45.1)\end{array}$ & $\begin{array}{c}107 \\
(50.9)\end{array}$ & $\begin{array}{c}101 \\
(41.6)\end{array}$ & $\begin{array}{c}55 \\
(50.0)\end{array}$ & $\begin{array}{c}162 \\
(45.5)\end{array}$ & $\begin{array}{c}27 \\
(42.9)\end{array}$ & $\begin{array}{c}67 \\
(40.1)\end{array}$ & $\begin{array}{c}46 \\
(52.3)\end{array}$ & $\begin{array}{c}76 \\
(44.2)\end{array}$ & $\begin{array}{c}141 \\
(42.9)\end{array}$ & $\begin{array}{c}19 \\
(45.2)\end{array}$ & $\begin{array}{c}950 \\
(44.6)\end{array}$ \\
\hline Missing patients sex, $n(\%)$ & $\begin{array}{c}0 \\
(0.0)\end{array}$ & $\begin{array}{c}0 \\
(0.0)\end{array}$ & $\begin{array}{c}0 \\
(0.0)\end{array}$ & $\begin{array}{c}4 \\
(1.7)\end{array}$ & $\begin{array}{c}0 \\
(0.0)\end{array}$ & $\begin{array}{c}0 \\
(0.0)\end{array}$ & $\begin{array}{c}1 \\
(1.6)\end{array}$ & $\begin{array}{c}0 \\
(0.0)\end{array}$ & $\begin{array}{c}0 \\
(0.0)\end{array}$ & $\begin{array}{c}1 \\
(0.6)\end{array}$ & $\begin{array}{c}7 \\
(2.1)\end{array}$ & $\begin{array}{c}0 \\
(0.0)\end{array}$ & $\begin{array}{c}13 \\
(0.6)\end{array}$ \\
\hline 0 comorbidities, $n$ (\%) & $\begin{array}{c}29 \\
(21.9)\end{array}$ & $\begin{array}{c}121 \\
(56.3)\end{array}$ & $\begin{array}{c}30 \\
(14.3)\end{array}$ & $\begin{array}{c}155 \\
(63.8)\end{array}$ & $\begin{array}{c}55 \\
(50.0)\end{array}$ & $\begin{array}{l}219 \\
(61.5)\end{array}$ & $\begin{array}{c}24 \\
(38.1)\end{array}$ & $\begin{array}{c}52 \\
(31.1)\end{array}$ & $\begin{array}{c}30 \\
(34.1)\end{array}$ & $\begin{array}{c}70 \\
(40.7)\end{array}$ & $\begin{array}{c}191 \\
(58.1)\end{array}$ & $\begin{array}{c}19 \\
(45.2)\end{array}$ & $\begin{array}{c}995 \\
(46.8)\end{array}$ \\
\hline 1 comorbidity, $n(\%)$ & $\begin{array}{c}64 \\
(48.5)\end{array}$ & $\begin{array}{c}56 \\
(26.1)\end{array}$ & $\begin{array}{c}109 \\
(51.9)\end{array}$ & $\begin{array}{c}41 \\
(16.9)\end{array}$ & $\begin{array}{c}22 \\
(20.0)\end{array}$ & $\begin{array}{c}62 \\
(17.4)\end{array}$ & $\begin{array}{c}23 \\
(36.5)\end{array}$ & $\begin{array}{c}65 \\
(38.9)\end{array}$ & $\begin{array}{c}36 \\
(40.9)\end{array}$ & $\begin{array}{c}51 \\
(29.7)\end{array}$ & $\begin{array}{c}87 \\
(26.4)\end{array}$ & $\begin{array}{c}17 \\
(40.5)\end{array}$ & $\begin{array}{c}633 \\
(29.8)\end{array}$ \\
\hline 2 comorbidities, $n$ (\%) & $\begin{array}{c}28 \\
(21.2)\end{array}$ & $\begin{array}{c}31 \\
(14.4)\end{array}$ & $\begin{array}{c}54 \\
(25.7)\end{array}$ & $\begin{array}{c}41 \\
(16.9)\end{array}$ & $\begin{array}{c}22 \\
(21.6)\end{array}$ & $\begin{array}{c}63 \\
(17.7)\end{array}$ & $\begin{array}{c}12 \\
(19.1)\end{array}$ & $\begin{array}{c}36 \\
(21.6)\end{array}$ & $\begin{array}{c}14 \\
(15.9)\end{array}$ & $\begin{array}{c}37 \\
(21.5)\end{array}$ & $\begin{array}{c}37 \\
(11.3)\end{array}$ & $\begin{array}{c}6 \\
(14.3)\end{array}$ & $\begin{array}{c}381 \\
(17.9)\end{array}$ \\
\hline $3 \geq$ comorbidities, $n(\%)$ & $\begin{array}{c}11 \\
(8.3)\end{array}$ & $\begin{array}{c}7 \\
(3.3)\end{array}$ & $\begin{array}{c}17 \\
(8.1)\end{array}$ & $\begin{array}{c}6 \\
(2.5)\end{array}$ & $\begin{array}{c}11 \\
(10.0)\end{array}$ & $\begin{array}{c}12 \\
(3.4)\end{array}$ & $\begin{array}{c}4 \\
(6.4)\end{array}$ & $\begin{array}{c}14 \\
(8.4)\end{array}$ & $\begin{array}{c}8 \\
(9.1)\end{array}$ & $\begin{array}{c}14 \\
(8.1)\end{array}$ & $\begin{array}{c}14 \\
(4.3)\end{array}$ & $\begin{array}{c}0 \\
(0.0)\end{array}$ & $\begin{array}{l}118 \\
(5.5)\end{array}$ \\
\hline Number of clinicians: $n$ (\%) & 31 & 36 & 43 & 33 & 25 & 36 & 24 & 39 & 32 & 20 & 44 & 15 & 378 \\
\hline Female clinicians, $n$ (\%) & $\begin{array}{c}15 \\
(54.55)\end{array}$ & $\begin{array}{c}11 \\
(30.56)\end{array}$ & $\begin{array}{c}15 \\
(34.9)\end{array}$ & $\begin{array}{c}13 \\
(39.4)\end{array}$ & $\begin{array}{c}2 \\
(8.0)\end{array}$ & $\begin{array}{c}14 \\
(38.9)\end{array}$ & $\begin{array}{c}13 \\
(54.2)\end{array}$ & $\begin{array}{c}16 \\
(41.0)\end{array}$ & $\begin{array}{c}0 \\
(0.0)\end{array}$ & $\begin{array}{c}0 \\
(0.0)\end{array}$ & $\begin{array}{c}24 \\
(54.6)\end{array}$ & $\begin{array}{c}5 \\
(33.3)\end{array}$ & $\begin{array}{c}128 \\
(33.9)\end{array}$ \\
\hline Male clinicians, $n(\%)$ & $\begin{array}{c}16 \\
(45.45)\end{array}$ & $\begin{array}{c}18 \\
(50.0)\end{array}$ & $\begin{array}{c}28 \\
(65.2)\end{array}$ & $\begin{array}{c}20 \\
(60.6)\end{array}$ & $\begin{array}{c}8 \\
(32.0)\end{array}$ & $\begin{array}{c}10 \\
(27.8)\end{array}$ & $\begin{array}{c}11 \\
(45.8)\end{array}$ & $\begin{array}{c}23 \\
(59.0)\end{array}$ & $\begin{array}{c}3 \\
(9.4)\end{array}$ & $\begin{array}{c}1 \\
(5.0)\end{array}$ & $\begin{array}{c}20 \\
(45.4)\end{array}$ & $\begin{array}{c}10 \\
(66.7)\end{array}$ & $\begin{array}{c}168 \\
(44.4)\end{array}$ \\
\hline $\begin{array}{l}\text { Clinicians with missing sex, } \\
n(\%)\end{array}$ & $\begin{array}{c}0 \\
(0.0)\end{array}$ & $\begin{array}{c}7 \\
(19.4)\end{array}$ & $\begin{array}{c}0 \\
(0.0)\end{array}$ & $\begin{array}{c}0 \\
(0.0)\end{array}$ & $\begin{array}{c}15 \\
(60.0)\end{array}$ & $\begin{array}{c}12 \\
(33.3)\end{array}$ & $\begin{array}{c}0 \\
(0.0)\end{array}$ & $\begin{array}{c}0 \\
(0.0)\end{array}$ & $\begin{array}{c}29 \\
(90.6)\end{array}$ & $\begin{array}{c}19 \\
(95.0)\end{array}$ & $\begin{array}{c}0 \\
(0.0)\end{array}$ & $\begin{array}{c}0 \\
(0.0)\end{array}$ & $\begin{array}{c}82 \\
(21.7)\end{array}$ \\
\hline Clinicians' cadre: CO, $n(\%)$ & $\begin{array}{c}0 \\
(0.0)\end{array}$ & $\begin{array}{c}0 \\
(0.0)\end{array}$ & $\begin{array}{c}0 \\
(0.0)\end{array}$ & $\begin{array}{c}2 \\
(6.1)\end{array}$ & $\begin{array}{c}3 \\
(12.0)\end{array}$ & $\begin{array}{c}0 \\
(0.0)\end{array}$ & $\begin{array}{c}0 \\
(0.0)\end{array}$ & $\begin{array}{c}0 \\
(0.0)\end{array}$ & $\begin{array}{c}1 \\
(3.1)\end{array}$ & $\begin{array}{c}0 \\
(0.0)\end{array}$ & $\begin{array}{c}0 \\
(0.0)\end{array}$ & $\begin{array}{c}0 \\
(0.0)\end{array}$ & $\begin{array}{c}6 \\
(1.6)\end{array}$ \\
\hline $\begin{array}{l}\text { Clinicians' cadre: CO } \\
\text { interns, } n(\%)\end{array}$ & $\begin{array}{c}20 \\
(64.5)\end{array}$ & $\begin{array}{c}18 \\
(50.0)\end{array}$ & $\begin{array}{c}31 \\
(72.1)\end{array}$ & $\begin{array}{c}20 \\
(60.6)\end{array}$ & $\begin{array}{c}2 \\
(8.0)\end{array}$ & $\begin{array}{c}14 \\
(38.9)\end{array}$ & $\begin{array}{c}16 \\
(66.7)\end{array}$ & $\begin{array}{c}29 \\
(74.4)\end{array}$ & $\begin{array}{c}1 \\
(3.1)\end{array}$ & $\begin{array}{c}0 \\
(0.0)\end{array}$ & $\begin{array}{c}25 \\
(56.82)\end{array}$ & $\begin{array}{c}8 \\
(53.3)\end{array}$ & $\begin{array}{c}184 \\
(48.7)\end{array}$ \\
\hline $\begin{array}{l}\text { Clinicians' cadre: } M O^{\ddagger}, \\
n(\%)\end{array}$ & $\begin{array}{c}1 \\
(3.2)\end{array}$ & $\begin{array}{l}12.8 \\
(2.8)\end{array}$ & $\begin{array}{c}0 \\
(0.0)\end{array}$ & $\begin{array}{c}0 \\
(0.0)\end{array}$ & $\begin{array}{c}0 \\
(0.0)\end{array}$ & $\begin{array}{c}1 \\
(2.8)\end{array}$ & $\begin{array}{c}0 \\
(0.0)\end{array}$ & $\begin{array}{c}1 \\
(2.6)\end{array}$ & $\begin{array}{c}0 \\
(0.0)\end{array}$ & $\begin{array}{c}1 \\
(5.0)\end{array}$ & $\begin{array}{c}1 \\
(2.3)\end{array}$ & $\begin{array}{c}0 \\
(0.0)\end{array}$ & $\begin{array}{c}6 \\
(1.6)\end{array}$ \\
\hline $\begin{array}{l}\text { Clinicians' cadre: } M O \\
\text { interns, } n(\%)\end{array}$ & $\begin{array}{c}10 \\
(32.3)\end{array}$ & $\begin{array}{c}10 \\
(27.8)\end{array}$ & $\begin{array}{c}12 \\
(27.9)\end{array}$ & $\begin{array}{c}11 \\
(33.3)\end{array}$ & $\begin{array}{c}5 \\
(20.0)\end{array}$ & $\begin{array}{c}9 \\
(25.0)\end{array}$ & $\begin{array}{c}7 \\
(29.2)\end{array}$ & $\begin{array}{c}9 \\
(23.1)\end{array}$ & $\begin{array}{c}1 \\
(3.1)\end{array}$ & $\begin{array}{c}0 \\
(0.0)\end{array}$ & $\begin{array}{c}18 \\
(40.9)\end{array}$ & $\begin{array}{c}7 \\
(46.7)\end{array}$ & $\begin{array}{c}99 \\
(26.2)\end{array}$ \\
\hline $\begin{array}{l}\text { Clinicians with missing } \\
\text { cadre, } n(\%)\end{array}$ & $\begin{array}{c}0 \\
(0.0)\end{array}$ & $\begin{array}{c}7 \\
(19.4)\end{array}$ & $\begin{array}{c}0 \\
(0.0)\end{array}$ & $\begin{array}{c}0 \\
(0.0)\end{array}$ & $\begin{array}{c}15 \\
(60.0)\end{array}$ & $\begin{array}{c}12 \\
(33.3)\end{array}$ & $\begin{array}{c}1 \\
(4.1)\end{array}$ & $\begin{array}{c}0 \\
(0.0)\end{array}$ & $\begin{array}{c}29 \\
(90.6)\end{array}$ & $\begin{array}{c}19 \\
(95.0)\end{array}$ & $\begin{array}{c}0 \\
(0.0)\end{array}$ & $\begin{array}{c}0 \\
(0.0)\end{array}$ & $\begin{array}{c}83 \\
(21.9)\end{array}$ \\
\hline
\end{tabular}

${ }^{\ddagger}$ CO-Clinical Officer, MO-Medical Officer, H1-H12 denote hospitals participating in the trial.

(MO) combining medical officers and medical officer interns, respectively. Approximately, 42\% $(903 / 2,127)$ of patients were aged between 2 and 11 months and 45\% (950/2,127) were females. Patient's sex was missing in $0.7 \%(17 / 2,127)$ of case records (Table $\mathbf{1}$ ).

Examining pneumonia PAQC score over time graphically, hospitals in the standard A\&F arm (red curve) exhibited a higher mean PAQC score at baseline with no significant fluctuations over time (Figure 1). On the other hand, hospitals assigned to enhanced A\&F arm (blue curve) had a lower mean PAQC score at baseline which rapidly improved toward higher score in the first 6 months of follow-up. Although enhanced A\&F arm's trend line surpassed that of standard A\&F arm after 6 months of follow-up, the $95 \%$ confidence bands of the two intervention arms overlapped substantially (Figure 1).

An assessment of missing data patterns suggested a multivariate missing data pattern (Figure A1 in Supplementary Material). The missing data pattern further revealed similarities between of missing clinician's cadre and sex. That is, nearly all clinicians with missing sex had missing cadre as well. Further investigations into missing data patterns showed that missing clinicians' cadre and sex only occurred in six out of 12 hospitals (Figure 2).

Logistic regression results on plausible mechanisms underlying pneumonia trial data indicated that the probability of missing patient's sex was neither dependent on the outcome 
(PAQC score) nor fully observed covariates (interaction between intervention arm and follow up time in months, hospital admission workload, and malaria prevalence, patient's age group, and the number of presenting comorbid illnesses). That is, the $P$-values were $>0.05$ suggesting a MCAR mechanism (Table A1 in Supplementary Material). On the other hand, the probabilities of missing clinician's cadre and gender were dependent on both the outcome and fully observed covariates suggesting evidence against MCAR (Table A1 in Supplementary Material). Therefore,

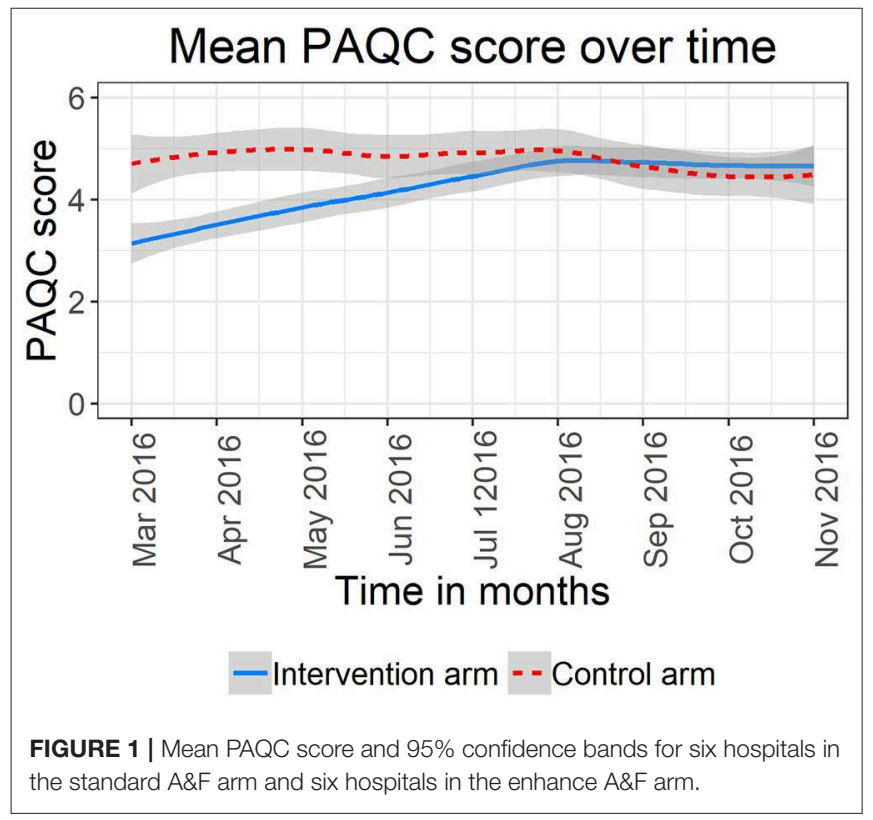

we imputed missing data assuming a MAR mechanism. MI diagnostic test indicated satisfactory convergence (Figure A2 in Supplementary Material).

\section{Random Effects and GEE Model Results}

Test for proportional odds assumption was not statistically significant at $5 \%$ level $(P=0.17)$. Therefore, we assumed parallel logits and fitted proportional odds models to complete case records and imputed datasets. In Table 2, we present the likelihood ratio test and Wald test results for proportional odds random effects and GEE model, respectively. After MI of missing covariates, we observed consistent results between the random effects model and the GEE model in terms of statistical significance of covariates of interest (Table 2). Specifically, we found statistically significant interaction effect between intervention arm and follow-up time. Similarly, admission workload at hospital level was significant at $5 \%$ level. At patients' level, age and the number of comorbidities were statistically significant while at clinicians' level, sex showed significant effect on pneumonia PAQC score (Table 2).

In Table 3, we present proportional odds ratios and the corresponding 95\% confidence interval obtained after fitting the random intercepts model and GEE models before and after multilevel multiple imputation. Standard errors before and after MI are presented in Table A2 (Supplementary Material). For the GEE model, we reported robust (empirically corrected) standard errors which were in agreement with model based (naive) standard errors (Table A2 in Supplementary Material). Under complete case analysis, only 1,619/2,127 (76.1\%) case records were considered.

This loss information led to larger standard errors comparison to those obtained after MI of missing covariates in both random

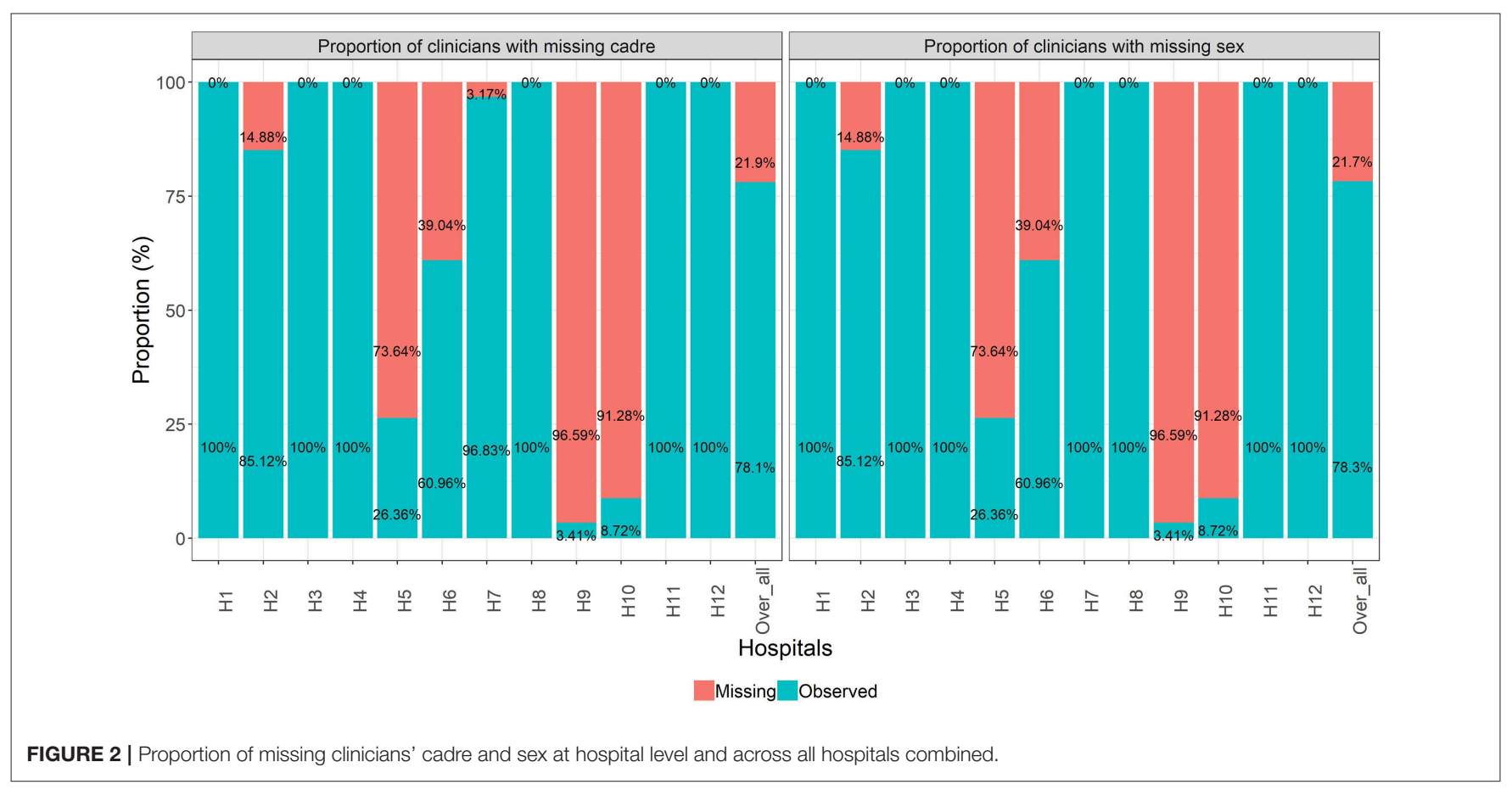


TABLE 2 | Likelihood ratio test and Wald test statistics for random effects model and GEE model under complete case analysis and after multilevel multiple imputation of missing covariates.

\begin{tabular}{|c|c|c|c|c|c|c|c|c|}
\hline \multirow[b]{3}{*}{ Effect } & \multicolumn{4}{|c|}{ Random effects model } & \multicolumn{4}{|c|}{ GEE model } \\
\hline & \multicolumn{2}{|c|}{$\begin{array}{c}\text { Complete case analysis } N= \\
1,619(76.1 \%)\end{array}$} & \multicolumn{2}{|c|}{$\begin{array}{c}\text { Multilevel MI } \\
N=2,127(100 \%)\end{array}$} & \multicolumn{2}{|c|}{$\begin{array}{l}\text { Complete case analysis } \\
\qquad N=1,619(76.1 \%)\end{array}$} & \multicolumn{2}{|c|}{$\begin{array}{c}\text { Multilevel MI } \\
N=2,127(100 \%)\end{array}$} \\
\hline & LRT & $P$-value & LRT & $P$-value & Wald test & $P$-value & Wald test & $P$-value \\
\hline Patients' age & 3.49 & 0.06 & 4.66 & 0.03 & 4.18 & 0.04 & 7.81 & 0.01 \\
\hline Patients' sex & 0.08 & 0.77 & 0.01 & 0.92 & 0.003 & 0.96 & 0.02 & 0.88 \\
\hline Comorbidities & 4.46 & 0.02 & 4.83 & 0.03 & 2.42 & 0.49 & 5.48 & 0.02 \\
\hline Clinicians' sex & 5.06 & 0.02 & 4.02 & 0.04 & 6.32 & 0.01 & 4.47 & 0.03 \\
\hline Clinicians' cadre & 0.01 & 0.91 & 0.23 & 0.63 & 1.36 & 0.24 & 2.96 & 0.08 \\
\hline Hospital workload & 0.143 & 0.71 & 3.39 & 0.04 & 1.46 & 0.23 & 4.95 & 0.03 \\
\hline Malaria prevalence & 0.067 & 0.79 & 1.35 & 0.25 & 0.98 & 0.32 & 0.012 & 0.91 \\
\hline Time (months) & 11.98 & $<0.001$ & 14.16 & $<0.001$ & 11.37 & 0.003 & 11.16 & $<0.001$ \\
\hline Enhanced A\&F arm & 28.58 & $<0.001$ & 17.51 & $<0.001$ & 28.86 & $<0.001$ & 17.76 & $<0.001$ \\
\hline Time $\times$ Enhanced A\&F & 14.92 & 0.02 & 14.16 & $<0.001$ & 17.85 & $<0.001$ & 9.45 & $<0.001$ \\
\hline
\end{tabular}

LRT, Likelihood ratio test; A\&F, Audit and feedback; MI, Multiple imputation; GEE, Generalized estimating equations.

effects and GEE model families. Furthermore, the proportional odds ratios were consistently smaller under complete case analyses compared to those obtained after MI (Table 3). These results were an indication of bias and inefficiency of parameters estimated under complete case analysis. The six PAQC score intercepts presented in Table 3 denote thresholds (cut points) differentiating adjacent levels of the response variable. For example, intercept 1 in Table 3 denote the odds of PAQC score $=1$ vs. PAQC score $\geq 2$ for a female patient aged $2-11$ months admitted with no comorbidities admitted by a male medical officer in a high workload hospitals located in high malaria prevalence region. The individual fixed effect parameters are the proportional odds ratios of individual variables on PAQC score holding all other variables in the model constant.

From study results, enhanced audit and feedback led to improve uptake of new pneumonia pediatric guideline over time. For instance, considering a patient admitted in an intervention hospital (enhanced audit and feedback arm), the odds of PAQC score $=1$ vs. PAQC score $\geq 2$ were 1.16 (95\% CI: $1.02-$ 1.308) times higher the odds of a patients admitted in a control hospital, for a unit increase in follow-up time and holding other variables at reference levels. Likewise, for a patient admitted in an intervention hospital, the odds of PAQC score $=1$ vs. PAQC score $\geq 2$ were 1.29 (95\% CI: $1.17-1.482$ ) times higher the odds of a patients admitted in a control hospital, for a unit increase in follow-up month (GEE model after MI). These interpretations hold for all other response (PAQC score) levels.

The study results also exhibited shifts in statistical significance before and after multiple imputation for selected variable. Specifically, adjusting for other variables, complete cases analysis lead to insignificant difference between low and high admission workload hospitals on levels of PAQC score in both random effects model and GEE model where the 95\% CI confidence intervals contained the value 1 . But after $\mathrm{MI}$, the odds of higher pneumonia PAQC score in low workload hospitals were 1.12 (95\% CI: $1.08-1.372$ ) and 1.40 (95\% CI: $1.103-2.063$ ) times higher than for high workload hospitals for the random intercepts and GEE model, respectively (Table 3).

With regard to random effects model, the variance component between clinicians and the corresponding standard error were inflated under complete cases analysis. A possible explanation for this results is that clinicians with missing cadre and sex were discarded under complete case analysis resulting to fewer number of clinicians (clusters) hence inflated clinicians' variability. On the other hand, all clinicians were retained after MI hence lower variability between clinicians.

\section{DISCUSSION}

This study sought to investigate the effect of enhanced A\&F on routine pediatric pneumonia care in 12 Kenyan hospitals during a cluster randomized trial. In the analysis we adjusted for patients, clinicians, and hospital levels factors while accounting for covariate missingness across the three levels of hierarchy. The number of pneumonia admissions varied widely across hospitals during the trial period. The outcome of interest (pneumonia PAQC score) is a composite measure representing multiple aspects of pediatric pneumonia care on a 7-point ordinal scale. The advantage of using composite outcomes over individual performance measures is increased statistical efficiency (43-47). Although we reported and analyzed a fully observed outcome, we note that variations in pneumonia PAQC on the 7-point ordinal scale was attributable to missing data in some of the subcomponents in addition to inappropriate pneumonia care across domains of care (12). Specifically, missing components and those corresponding to inappropriate care were scored zero. Among covariates, clinician variables exhibited the highest proportions of missingness. Approximately $21 \%$ of all admitting clinicians had missing sex and cadre, respectively. These observations were consistent with previous results of a cluster randomized trial evaluating the effectiveness of a multifaceted intervention to improve admission pediatric care in eight Kenyan 
TABLE 3 | Odds ratios (95\% confidence intervals) estimated under complete case analysis and after multilevel multiple imputation of missing covariates.

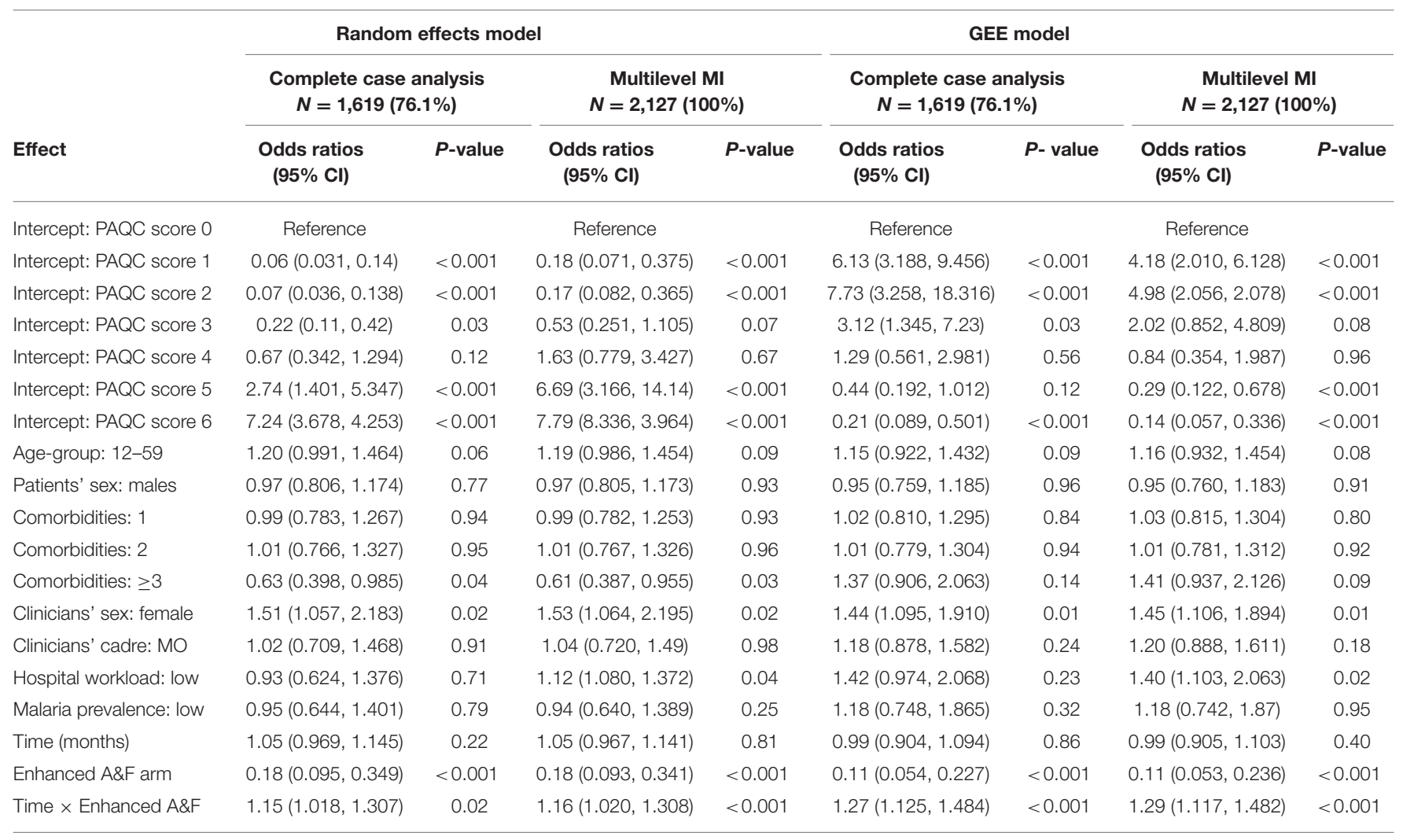

hospitals $(10,48)$. In the said study, 14 and $20 \%$ of the clinicians had missing sex and years of experience, respectively.

In contrast, patient level variables were fully observed except patient's sex which had $<1 \%$ missingness. The sharp contrast missingness between clinicians and patients level variables could be due the fact that continued CIN audit and feedback reports focus on the documentation of patient level variables rather than documentation of clinicians' characteristics. Through preliminary investigations, we established that missing clinicians' characteristics occurred in six out of 12 hospitals participating in the trial. The patterns of missingness in the two clinicians level variables was highly correlated. That is, clinicians who did not document their sex were also likely not to document their cadre and vice versa.

To alleviate bias and inefficiency, we used multiple imputation within the joint modeling (JM) imputation framework assuming a MAR mechanism $(10,30,31)$. Although JM imputation framework does not address the full range of complexities that are typical of multilevel data $(22,23)$, it was preferred due to its flexibility coupled with recent statistical software developments in handling categorical variables with more than two levels in second and higher levels of hierarchy (36).

Consistent with our expectations, results demonstrated that multilevel imputation led to more precise parameter estimates compared to complete case analyses in both random effects and GEE models. Adjusting for patients, clinicians and hospital level factors, enhanced A\&F improved uptake and adherence to recommended pediatric pneumonia guidelines over time among children aged 2-59 months admitted in six CIN hospitals during the trial period compared to standard A\&F on general inpatient pediatric care. The significant difference in the uptake of the pneumonia guidelines between the intervention arms could be due to difference in baseline performance observed in the Loess curves. That is, control hospitals exhibited high baseline performance (on average) thus leaving smaller room for improvement compared to low baseline performance in the enhanced $A \& F$ arm hence larger room for improvement over time. These results were consistent with those of the primary analysis (24).

A key difference between our study and that primary analysis is that whereas we analyzed a composite outcome spanning three quality of care domain, Ayieko et al. (24) considered proportion of patients with correct pneumonia classification and treatment, respectively. Furthermore, our study accounted for clinicians' characteristics in addition to patients and hospitals level characteristics accounted for in the primary analysis. From results, the quality of pneumonia care differed between male and female clinicians. It was also evident that junior clinicians 
(medical officers and clinical officer interns) were responsible for much care during the trial period. However, the quality of care provided did not differ between the cadres. The high number of interns is an indication that hospitals in the trial were teaching and referral hospitals.

\section{Strengths and Implications of the Study}

In this study, we investigated plausible missing data mechanism underlying pneumonia trial data. Though often ignored, this step is important in assessing and understanding the implications of missingness in a given data set under analysis. That is, inefficient estimates or both biased and inefficient estimates. In addition to missing data mechanism, we evaluated missing data patterns underlying the trial data set. This was useful in revealing trends and gaps in the quality of routine care. Insight into such information is useful when designing cost effective follow-up or new interventions programmes for optimal and efficient utilization of already stretched resources (49). For instance, based on our study results, a follow up intervention programme aimed at improving documentation and reporting of clinician characteristics should be directed to specific hospitals low documentation of clinicians' level data while resources in hospitals with good documentation practices should be directed elsewhere.

To address missing data, we employed recent statistical software tools to impute missing variables in routine pediatric data. Our choice of imputation tools and method was in consideration of the hierarchical structure of the data and type of variables in the data set. This ensured compatibility between imputation and analysis models of interest thus minimizing bias in parameter estimates $(10,23)$. Further, our choice of proportion odds models to analyze the ordinal outcome was ascertained through formal test further enhancing the validity of our study results. In instances when the proportional odds assumptions are violated, multinomial logistic regression model is recommended (40). In contrast to previous studies reporting quality of inpatient pediatric routine care in CIN hospitals $(3,13,15)$, our study accounted for clinicians who are essential for the delivery of health intervention (16). Ignoring variation at clinician level may lead to biased estimates, overestimation or underestimation of variations in other levels of clustering (50).

\section{LIMITATIONS}

A limitation of this study is that we relied on data collected after patient discharge. Therefore, we are unable to ascertain if patients received pneumonia care as documented by health workers (24). We imputed missing data assuming MAR mechanism. Therefore, sensitivity analyses will be undertaken to explore the robustness of the inferences to MAR assumptions.

\section{CONCLUSION}

Adjusting for hospitals, admitting clinicians, and patient level factors, enhanced audit, and feedback improved uptake of WHO recommended pediatric pneumonia guidelines compared to standard audit and feedback. Additionally, female clinicians and hospitals with low admission workload were associated with higher uptake of the new pediatric pneumonia guidelines during the trial period. In both random effects and marginal model, parameter estimates were biased and inefficient under complete case analysis. Therefore, multiple imputation is recommended. When analyzing partially observed data with more than one level of clustering, it is paramount to accounts for the hierarchical structure in the imputation model to ensure compatibility with analysis models of interest and hence alleviate bias.

\section{ETHICS STATEMENT}

The Kenya Ministry of Health and Kenya Medical Research Institute's Scientific and Ethical Review Unit approved the use of de-identified patient data obtained through retrospective review of medical records without individual patient consent.

\section{AUTHOR CONTRIBUTIONS}

SG conducted the analyses. Feedback on the analytic approach was provided by EN, NO, PA, and ME. SG drafted the initial manuscript with feedback on subsequent drafts provided by all authors who then approved the final manuscript.

\section{FUNDING}

This work was supported through the DELTAS Africa Initiative Grant No. 107754/Z/15/Z-DELTAS Africa SSACAB. The DELTAS Africa Initiative is an independent funding scheme of the African Academy of Sciences (AAS)'s Alliance for Accelerating Excellence in Science in Africa (AESA) and supported by the New Partnership for Africa's Development Planning and Coordinating Agency (NEPAD Agency) with funding from the Wellcome Trust (Grant No. 107754/Z/15/Z) and the UK government. The views expressed in this publication are those of the author(s) and not necessarily those of AAS, NEPAD Agency, Wellcome Trust or the UK government.

Funds from the Wellcome Trust (Grant No. 097170) awarded to $\mathrm{ME}$ as a senior Fellowship together with additional funds from a Wellcome Trust core grant awarded to the KEMRI-Wellcome Trust Research Programme (Grant No. 092654) supported CIN data collection.

\section{ACKNOWLEDGMENTS}

We would like to thank the Ministry of Health who gave permission for this work to be developed and have supported the implementation of the CIN together with the county health executives and all hospital management teams. We are grateful to the Kenya Pediatric Association for promoting the aims of the CIN and the support they provide through their officers and membership. We also thank the hospital teams involved in service delivery for the sick child. This work is published with the permission of the Director of KEMRI. The CIN 
team who contributed to the design of the data collection tools, conduct of the work, collection of data, and data quality assurance that form the basis of this report and who saw and approved the report's findings include: Grace Irimu, Samuel Akech, Ambrose Agweyu, Michuki Maina, Jacquie Oliwa, David Gathara, Paul Mwaniki, Morris Ogero, James Wafula, Thomas Julius, George Mbevi, Mercy Chepkirui, Abraham Lagat, Lucas Malla (KEMRI-Wellcome Trust Research Programme); Samuel N'garng'ar (Vihiga County Hospital), Ivan Muroki (Kakamega County Hospital), David Kimutai and Loice Mutai (Mbagathi County Hospital), Caren Emadau and Cecilia Mutiso (Mama Lucy Kibaki Hospital), Charles Nzioki (Machakos Level 5 Hospital), Francis Kanyingi and Agnes Mithamo (Nyeri County Hospital), Margaret Kuria (Kisumu East County Hospital), Samuel Otido (Embu County Hospital), Grace Wachira and Alice Kariuki (Karatina County Hospital), Peris Njiiri (Kerugoya County Hospital), Rachel Inginia and Melab Musabi (Kitale County Hospital), Hilda Odeny (Busia County Hospital), Grace

\section{REFERENCES}

1. Harries AD, Zachariah R, Maher D. The power of data: using routinely collected data to improve public health programmes and patient outcomes in low-and middle-income countries. Trop Med Inter Health. (2013) 18:1154-6. doi: $10.1111 /$ tmi. 12159

2. Omore R, Tate JE, O’Reilly CE, Ayers T, Williamson J, Moke F, et al. Epidemiology, seasonality and factors associated with rotavirus infection among children with moderate-to-severe diarrhea in rural western Kenya, 2008-2012: the global enteric multicenter study (GEMS). PLoS ONE. (2016) 11:e0160060. doi: 10.1371/journal.pone.0 160060

3. Gachau S, Ayieko P, Gathara D, Mwaniki P, Ogero M, Akech S, et al. Does audit and feedback improve the adoption of recommended practices? Evidence from a longitudinal observational study of an emerging clinical network in Kenya. BMJ Global Health. (2017) 2:e000468. doi: 10.1136/bmjgh-2017-000468

4. Ivers N, Jamtvedt G, Flottorp S, Young JM, Odgaard-Jensen J, French SD, et al. Audit and feedback: effects on professional practice and healthcare outcomes. Cochrane Database Syst Rev. (2012) 13:CD000259. doi: 10.1002/14651858.CD000259.pub3

5. Ayieko P, Irimu G, English M. Effect of enhanced feedback to hospitals that are part of an emerging clinical information network on uptake of revised childhood pneumonia treatment policy: study protocol for a cluster randomized trial. Trials. (2017) 18:416. doi: 10.1186/s13063-0172152-8

6. English M. Designing a theory-informed, contextually appropriate intervention strategy to improve delivery of paediatric services in Kenyan hospitals. Implement Sci. (2013) 8:39. doi: 10.1186/1748-59 08-8-39

7. Tuti T, Bitok M, Paton C, Makone B, Malla L, Muinga N, et al. Innovating to enhance clinical data management using non-commercial and open source solutions across a multi-center network supporting inpatient pediatric care and research in Kenya. J Am Med Inform Assoc. (2016) 23:184-92. doi: 10.1093/jamia/ocv028

8. Lloyd JE, Obradović J, Carpiano RM, Motti-Stefanidi F. JMASM 32: multiple imputation of missing multilevel, longitudinal data: a case when practical considerations trump best practices? J Modern Appl Stat Method. (2013) 12:29. doi: $10.22237 / j m a s m / 1367382480$

9. Houngbo PT, Buning TDC, Bunders J, Coleman HL, Medenou D, Dakpanon L, et al. Ineffective healthcare technology management in Benin's public health sector: the perceptions of key actors and their ability to
Ochieng and Lydia Thuranira (Kiambu County Hospital); Priscilla Oweso (Vihiga County Hospital), Ernest Namayi (Mbale Rural Health and Demonstration Centre), Benard Wambani and Samuel Soita (Kakamega Provincial General Hospital), Joseph Nganga (Mbagathi District Hospital), Margaret Waweru and John Karanja (Kiambu County Hospital), Susan Owano (Mama Lucy Kibaki Hospital), Esther Muthiani (Machakos Level 5 Hospital), Alfred Wanjau (Nyeri Level 5 hospital), Larry Mwallo (Kisumu East District Hospital), Lydia Wanjiru (Embu Provincial General Hospital), Consolata Kinyua (Karatina District Hospital), Mary Nguri (Kerugoya District Hospital), and Dorothy Munjalu (Kitale District Hospital).

\section{SUPPLEMENTARY MATERIAL}

The Supplementary Material for this article can be found online at: https://www.frontiersin.org/articles/10.3389/fpubh. 2019.00198/full\#supplementary-material

address the main problems. Inter J Health Policy Manag. (2017) 6:587. doi: 10.15171/ijhpm.2017.17

10. Carpenter JR, Kenward MG. Multiple Imputation and Its Applications. Chichester: John Wiley \& Sons (2013).

11. Rombach I, Gray AM, Jenkinson C, Murray DW, Rivero-Arias O. Multiple imputation for patient reported outcome measures in randomised controlled trials: advantages and disadvantages of imputing at the item, subscale or composite score level. BMC Med Res Methodol. (2018) 18:87. doi: 10.1186/s12874-018-0542-6

12. Opondo C, Allen E, Todd J, English M. The paediatric admission quality of care (PAQC) score: designing a tool to measure the quality of early inpatient paediatric care in a low-income setting. Trop Med Inter Health. (2016) 21:1334-45. doi: 10.1111/tmi.12752

13. Thomas J, Ayieko P, Ogero M, Gachau S, Makone B, Nyachiro W, et al. Blood transfusion delay and outcome in county hospitals in Kenya. Am J Trop Med Hyg. (2017) 96:511-7. doi: 10.4269/ajtmh.16-0735

14. Gathara D, English M, van Hensbroek MB, Todd J, Allen E. Exploring sources of variability in adherence to guidelines across hospitals in low-income settings: a multi-level analysis of a cross-sectional survey of 22 hospitals. Implement Sci. (2015) 10:1. doi: 10.1186/s13012-0150245-x

15. Agweyu A, Lilford RJ, English M. Appropriateness of clinical severity classification of new WHO childhood pneumonia guidance: a multihospital, retrospective, cohort study. Lancet Glob Health. (2018) 6:e74-83. doi: 10.1016/S2214-109X(17)30448-5

16. Rowe AK, de Savigny D, Lanata CF, Victora CG. How can we achieve and maintain high-quality performance of health workers in low-resource settings? Lancet. (2005) 366:1026-35. doi: 10.1016/S0140-6736(05)6 7028-6

17. Gachau S, Irimu G, Ayieko P, Akech S, Agweyu A, English M. Prevalence, outcome and quality of care among children hospitalized with severe acute malnutrition in Kenyan hospitals: a multi-site observational study. PLoS ONE. (2018) 13:e0197607. doi: 10.1371/journal.pone.0 197607

18. Hau DK, Chami N, Duncan A, Smart LR, Hokororo A, Kayange $\mathrm{NM}$, et al. Post-hospital mortality in children aged 2-12 years in Tanzania: a prospective cohort study. PLoS ONE. (2018) 13:e0202334. doi: 10.1371/journal.pone.0202334

19. Ogero M, Ayieko P, Boniface Makone TJ, Malla L, Oliwa J, Irimu G, et al. An observational study of monitoring of vital signs in children admitted to Kenyan hospitals: an insight into the quality of nursing care? J Glob Health. (2018) 8:010409. doi: 10.7189/jogh.08.010409 
20. Malla L, Perera-Salazar R, McFadden E, English M. Comparative effectiveness of injectable penicillin versus a combination of penicillin and gentamicin in children with pneumonia characterised by indrawing in Kenya: a retrospective observational study. BMJ Open. (2017) 7:e019478. doi: 10.1136/bmjopen-2017-019478

21. Drechsler J. Multiple imputation of multilevel missing dataRigor versus simplicity. J Educ Behav Stat. (2015) 40:69-95. doi: 10.3102/1076998614563393

22. Enders CK, Mistler SA, Keller BT. Multilevel multiple imputation: a review and evaluation of joint modeling and chained equations imputation. Psychol Method. (2016) 21:222. doi: 10.1037/met0 000063

23. Grund S, Lüdtke O, Robitzsch A. Multiple imputation of missing data for multilevel models: Simulations and recommendations. Org Res Method. (2018) 21:111-49. doi: 10.1177/10944281177 03686

24. Ayieko P, Irimu G, Ogero M, Mwaniki P, Malla L, Julius T, et al. Effect of enhancing audit and feedback on uptake of childhood pneumonia treatment policy in hospitals that are part of a clinical network: a cluster randomized trial. Implement Sci. (2019) 14:20. doi: 10.1186/s13012-0190868-4

25. Ayieko P, Ogero M, Makone B, Julius T, Mbevi G, Nyachiro W, et al. Characteristics of admissions and variations in the use of basic investigations, treatments and outcomes in Kenyan hospitals within a new Clinical Information Network. Arch Dis Child. (2016) 101:223-9. doi: 10.1136/archdischild-2015-309269

26. World Health Organization. Pocket Book of Hospital Care for Children: Guidelines for the Management of Common Childhood Illnesses, 2nd edn. Geneva: World Health Organization (2013).

27. Opondo C, Allen E, Todd J, English M. Association of the paediatric admission quality of care score with mortality in Kenyan hospitals: a validation study. Lancet Glob Health. (2018) 6:e203-10. doi: 10.1016/S2214-109X(17)3 0484-9

28. Rubin DB. Inference and missing data. Biometrika. (1976) 63:581-92. doi: 10.1093/biomet/63.3.581

29. Fitzmaurice G, Davidian M, Verbeke G, Molenberghs G. Longitudinal Data Analysis. New York, NY: Chapman \& Hall (2009).

30. Molenberghs G, Verbeke G. Models for Discrete Longitudinal Data. New York, NY: Springer (2005).

31. Molenberghs G, Kenward M. Missing Data in Clinical Studies. Chichester: John Wiley \& Sons, Ltd. (2007).

32. Rubin DB. Procedures with nonignorable nonresponse. In: Multiple Imputation for Nonresponse in Surveys. New York, NY: John Wiley \& Sons (1987) p. 202-43. doi: 10.1002/9780470316696

33. Meng X-L. Multiple-imputation inferences with uncongenial sources of input. Stat Sci. (1994) 9:538-58. doi: 10.1214/ss/1177010269

34. van Buuren S, Groothuis-Oudshoorn K. Mice: multivariate imputation by chained equations in R. J Stat Softw. (2011) 45:1-67. doi: 10.18637/jss.v0 45.i03

35. Bartlett JW, Seaman SR, White IR, Carpenter JR, Alzheimer's Disease Neuroimaging Initiative. Multiple imputation of covariates by fully conditional specification: accommodating the substantive model. Stat Method Med Res. (2015) 24:462-87. doi: 10.1177/0962280214521348

36. Quartagno M. Multiple Imputation for Individual Patient Data Meta-Analyses. London: London School of Hygiene \& Tropical Medicine (2016).

37. Gelman A, Rubin DB. Inference from iterative simulation using multiple sequences. Stat Sci. (1992) 7:457-72. doi: 10.1214/ss/11770 11136
38. Liang K-Y, Zeger SL. Longitudinal data analysis using generalized linear models. Biometrika. (1986) 73:13-22. doi: 10.1093/biomet/73.1.13

39. Zeger SL, Liang K-Y, Albert PS. Models for longitudinal data: a generalized estimating equation approach. Biometrics. (1988) 44:1049-60.

40. Agresti A. Categorical Data Analysis. New York, NY: John Wiley \& Sons (2002).

41. Van Buuren S. Flexible Imputation of Missing Data. Boca Raton, FL: Chapman \& Hall/CRC Press (2018).

42. Meng X-L, Rubin DB. Performing likelihood ratio tests with multiply-imputed data sets. Biometrika. (1992) 79:103-11. doi: 10.1093/biomet/79.1.103

43. Freemantle N, Calvert M, Wood J, Eastaugh J, Griffin C. Composite outcomes in randomized trials: greater precision but with greater uncertainty? JAMA. (2003) 289:2554-9. doi: 10.1001/jama.289.1 9.2554

44. Cordoba G, Schwartz L, Woloshin S, Bae H, Gøtzsche PC. Definition, reporting, and interpretation of composite outcomes in clinical trials: systematic review. BMJ. (2010) 341:c3920. doi: 10.1136/bm j.c3920

45. Eapen ZJ, Fonarow GC, Dai D, O’brien SM, Schwamm LH, Cannon $\mathrm{CP}$, et al. Comparison of composite measure methodologies for rewarding quality of care: an analysis from the American Heart Association's Get with The Guidelines program. Circul Cardiovasc Qual Outcomes. (2011) 4:610-8. doi: 10.1161/CIRCOUTCOMES.11 1.961391

46. Profit J, Kowalkowski MA, Zupancic JA, Pietz K, Richardson P, Draper D, et al. Baby-MONITOR: a composite indicator of NICU quality. Pediatrics. (2014) 134:74-82. doi: 10.1542/peds.2013-3552

47. Shwartz M, Restuccia JD, Rosen AK. Composite measures of health care provider performance: a description of approaches. Milbank Q. (2015) 93:788-825. doi: 10.1111/1468-0009.12165

48. Ayieko P, Ntoburi S, Wagai J, Opondo C, Opiyo N, Migiro S, et al. A multifaceted intervention to implement guidelines and improve admission paediatric care in Kenyan district hospitals: a cluster randomised trial. PLoS Med. (2011) 8:e1001018. doi: 10.1371/journal.pmed.1001018

49. Bitton A, Ratcliffe HL, Veillard JH, Kress DH, Barkley S, Kimball M, et al. Primary health care as a foundation for strengthening health systems in low-and middle-income countries. J General Intern Med. (2017) 32:566-71. doi: 10.1007/s11606-016-3898-5

50. Cook DA, Pencille LJ, Dupras DM, Linderbaum JA, Pankratz VS, Wilkinson JM. Practice variation and practice guidelines: Attitudes of generalist and specialist physicians, nurse practitioners, and physician assistants. PLoS ONE. (2018) 13:e0191943. doi: 10.1371/journal.pone.0191943

Conflict of Interest Statement: The authors declare that the research was conducted in the absence of any commercial or financial relationships that could be construed as a potential conflict of interest.

The handling Editor declared a shared affiliation, though no other collaboration, with several of the authors EN and PA, within the last two years.

Copyright (C) 2019 Gachau, Owuor, Njagi, Ayieko and English. This is an open-access article distributed under the terms of the Creative Commons Attribution License (CC $B Y)$. The use, distribution or reproduction in other forums is permitted, provided the original author(s) and the copyright owner(s) are credited and that the original publication in this journal is cited, in accordance with accepted academic practice. No use, distribution or reproduction is permitted which does not comply with these terms. 